\title{
Low-density lipoprotein cholesterol to high-density lipoprotein cholesterol ratio is the best surrogate marker for insulin resistance in non-obese Japanese adults
}

\author{
Ryuichi Kawamoto ${ }^{1,3^{*}}$, Yasuharu Tabara², Katsuhiko Kohara ${ }^{2}$, Tetsuro Miki ${ }^{2}$, Tomo Kusunoki ${ }^{1,3}$, Shuzo Takayama ${ }^{1}$, \\ Masanori Abe ${ }^{1}$, Tateaki Katoh ${ }^{3}$, Nobuyuki Ohtsuka ${ }^{3}$
}

\begin{abstract}
Background: The aim of the present study was to examine how lipid profiles are associated with insulin resistance in Japanese community-dwelling adults.

Methods: This cross-sectional study included 614 men aged $58 \pm 14$ (mean \pm standard deviation; range, 20-89) years and 779 women aged $60 \pm 12$ (range, 21-88) years. The study sample were 1,042 (74.8\%) non-obese (BMl < $\left.25.0 \mathrm{~kg} / \mathrm{m}^{2}\right)$ and $351(25.2 \%)$ overweight (BMI $\left.\geq 25 \mathrm{~kg} / \mathrm{m}^{2}\right)$ subjects. Insulin resistance was defined by homeostasis model assessment of insulin resistance (HOMA-IR) of at least 2.5. The areas under the curve (AUC) of the receiver operating characteristic curves (ROC) were used to compare the power of these serum markers.

Results: In non-obese subjects, the best marker of insulin resistance was low-density lipoprotein cholesterol (LDLC)/high-density lipoprotein cholesterol (HDL-C) ratio of 0.74 (95\% confidence interval (Cl), 0.66-0.80). The HDL-C, triglyceride (TG)/HDL-C ratio, and non-HDL-C also discriminated insulin resistance, as the values for AUC were 0.31 (95\% Cl, 0.24-0.38), $0.69(95 \% \mathrm{Cl}, 0.62-0.75)$ and $0.69(95 \% \mathrm{Cl}, 0.62-0.75)$, respectively. In overweight subjects, the AUC for TG and TG/HDL-C ratio were $0.64(0.58-0.71)$ and $0.64(0.57-0.70)$, respectively. The optimal cut-off point to identifying insulin resistance for these markers yielded the following values: TG/HDL-C ratio of $\geq 1.50$ and LDL-C/ HDL-C ratio of $\geq 2.14$ in non-obese subjects, and $\geq 2.20, \geq 2.25$ in overweight subjects. In non-obese subjects, the positive likelihood ratio was greatest for $L D L-C / H D L-C$ ratio.
\end{abstract}

Conclusion: In non-obese Japanese adults, LDL-C/HDL-C ratio may be the best reliable marker of insulin resistance.

\section{Background}

Being overweight is also a major worldwide public health problem. In Japanese adults, it was demonstrated that $29.3 \%$ of men and $19.5 \%$ of women are overweight (body mass index (BMI); weight $(\mathrm{kg}) /$ height $(\mathrm{m})^{2}, \geq 25$ $\mathrm{kg} / \mathrm{m}^{2}$ ), with approximately $3.3 \%$ of men and $3.2 \%$ of women designated as obese $\left(B M I \geq 30 \mathrm{~kg} / \mathrm{m}^{2}\right)$ [1]. Several large-scale studies have shown that overweight people, defined on the basis of a high BMI, increases the risk of hypertension, dyslipidemia, diabetes and

\footnotetext{
* Correspondence: rykawamo@yahoo.co.jp

'Department of Community Medicine, Ehime University Graduate School of Medicine; Ehime 791-0295, Japan

Full list of author information is available at the end of the article
}

developing cardiovascular disease (CVD) such as stroke and myocardial infarction than subjects with normal BMI [2-4]. Moreover, it has been suggested that individuals exist who are not overweight, but who, like people with overt obesity, also have hyperinsulinemia, are insulin resistant, and are predisposed to hypertriglyceridemia, type 2 diabetes mellitus, and premature cardiovascular disease [5,6]. Much investigation has been focused on insulin resistance as the primary determinant of atherosclerotic risk factors, independent of BMI [7].

On the other hand, insulin resistant persons also have a characteristic dyslipidemia [8] and measuring these variables might help identify insulin resistance. Plasma

\section{( Biomed Central}


triglycerides, high-density lipoprotein cholesterol (HDLC) $[9,10]$, and total cholesterol (T-C)/HDL-C are independently associated with insulin resistance and risk factors of CVD [11]. However, in Japanese communitydwelling persons, there are few studies to demonstrate a relationship between lipid profiles and insulin resistance, categorized by BMI.

We took advantage of the large representative sample of Japanese adults who participated at the time of their annual health examination. We investigated how lipid profiles were associated with insulin resistance in healthy Japanese adults. For this, we used cross-sectional data from community-dwelling participants without clinical diabetes.

\section{Methods}

\section{Subjects}

Participants were recruited at the time of their annual health examination in a rural town with a total population of 11,136 (as of April 2002) and located in Ehime prefecture, Japan, in 2002. Among the 9,133 adults (4,395 of them male) aged 19 to 90 years in this population, a random sample of 3,164 subjects $(34.6 \%)$ was recruited. Information on medical history, present conditions, and drugs was obtained by interview. Other characteristics, e.g., smoking and alcohol habits, and medication, were investigated by individual interviews using a structured questionnaire. Subjects taking medications for hypertension, diabetes, or dyslipidemia were excluded. The final study sample included 614 men and 779 women. This study was approved by the ethics committee of Ehime University School of Medicine, and written informed consent was obtained from each subject.

\section{Evaluation of confounding factors}

Information on demographic characteristics and risk factors was collected using clinical files. Body mass index was calculated by dividing weight (in kilograms) by the square of the height (in meters). We measured blood pressure in the right upper arm of participants in a sedentary position using an automatic oscillometric blood pressure recorder (BP-103i; Colin, Aichi, Japan) while the subjects were seated after having rested for at least $5 \mathrm{~min}$. Smoking status was defined as the number of cigarette packs per day multiplied by the number of years smoked (pack-year), and the participants were classified into never smokers, past smokers, light smokers ( $<30$ pack $\cdot y e a r)$ and heavy smokers ( $\geq 30$ pack $\cdot y e a r)$. The daily alcohol consumption was measured using the Japanese liquor unit in which a unit corresponds to $22.9 \mathrm{~g}$ of ethanol, and the participants were classified into never drinkers, occasional drinkers ( $<1$ unit/day), light drinkers (1-1.9 unit/day), and heavy drinkers ( $\geq 2$ unit/ day). T-C, TG, HDL-C, fasting blood glucose (FBG), creatinine (enzymatic method), uric acid, and immunoreactive insulin (IRI), and high molecular weight (HMW) adiponectin (FUJIREBIO, Tokyo, Japan) were measured during fasting low-density lipoprotein cholesterol (LDLC) levels were calculated using the Friedewald formula [12]. Participants with TG levels $\geq 400 \mathrm{mg} / \mathrm{dl}$ were excluded. Homeostasis of minimal assessment of insulin resistance (HOMA-IR) was calculated from FBG and IRI levels using the following formula; $\{\mathrm{FBG}(\mathrm{mg} / \mathrm{dL}) \times \mathrm{IRI}$ $(\mathrm{mU} / \mathrm{mL})\} / 405$ [13], and a borderline level of Insulin resistance was defined as HOMA-IR $\geq 1.6$ [13], and a definite level, HOMA-IR $\geq 2.5$ [14].

\section{Statistical analysis}

Statistical analysis was performed using PASW Statistics 17.0 (Statistical Package for Social Science Japan, Inc., Tokyo, Japan). All values are expressed as mean \pm standard deviation (SD), unless otherwise specified. Data for TG, FBG, HOMA-IR, and serum HMW adiponectin were skewed, and log-transformed for analysis. Subjects were divided into two groups based on BMI (non-obese, $<25.0 \mathrm{~kg} / \mathrm{m}^{2}$; overweight, $\geq 25.0 \mathrm{~kg} / \mathrm{m}^{2}$ ), and differences between the two groups were determined by Student's $\mathrm{t}$-test and $\chi^{2}$ test. In addition, areas under the receiver operating characteristic (ROC) curves were determined for each variable to identify the predictors of insulin resistance. Areas under the ROC curves are provided with standard errors. An ROC curve is a plot of the sensitivity (true positive) versus 1 -specificity (false positive) for each potential marker tested. The area under the ROC curve is a summary of the overall diagnostic accuracy of the test. The best markers have ROC curves that are shifted to the left with areas under the curve near unity. Nondiagnostic markers are represented by diagonals with areas under the ROC curves close to 0.5 . Likelihood ratios were calculated as the ratios of sensitivity - (1 - specificity) (positive likelihood ratio) and (1 - sensitivity) - specificity (negative likelihood ratio). A value of $P<0.05$ was considered significant.

\section{Results}

\section{Background factors of subjects categorized by BMI}

Table 1 shows the value of each background factor categorized by BMI. The subjects comprised 614 men aged $58 \pm 14$ (mean \pm standard deviation; range, 20-89) years and 779 women aged $60 \pm 12$ (range, 21-88) years. The mean BMI in the study sample was $23.1 \pm 3.1 \mathrm{~kg} / \mathrm{m}^{2}$, with 1,042 non-obese $\left(\mathrm{BMI}<25.0 \mathrm{~kg} / \mathrm{m}^{2}\right)(74.8 \%)$ and 351 overweight $\left(\mathrm{BMI} \geq 25 \mathrm{~kg} / \mathrm{m}^{2}\right)$ (25.2\%). Alcohol consumption, systolic blood pressure (SBP), diastolic blood pressure (DBP), T-C, TG, LDL-C, TG/HDL-C ratio, non-HDL-C, LDL-C/HDL-C ratio, and uric acid were significantly higher in subjects with a BMI $\geq 25.0 \mathrm{~kg} / \mathrm{m}^{2}$, but age, HDL-C and serum HMW adiponectin were 
Table 1 Characteristics of subjects categorized by body mass index

\begin{tabular}{|c|c|c|c|c|}
\hline $\begin{array}{l}\text { Body mass index } \dagger \\
\text { Characteristics }\end{array}$ & $\begin{array}{c}\text { Total } \\
\text { All } \\
\mathrm{N}=1,393\end{array}$ & $\begin{array}{l}\text { Non-obese } \\
\begin{array}{l}<25.0 \mathrm{~kg} / \mathrm{m}^{2} \\
\mathrm{~N}=1,042\end{array}\end{array}$ & $\begin{array}{l}\text { Overweight } \\
\begin{array}{c}\geq 25.0 \mathrm{~kg} / \mathrm{m}^{2} \\
\mathrm{~N}=351\end{array}\end{array}$ & $P$-value* \\
\hline Male sex, \% & 44.1 & 43.3 & 46.4 & 0.320 \\
\hline Age (years) & $59 \pm 13$ & $60 \pm 13$ & $57 \pm 12$ & 0.006 \\
\hline Body mass index $\left(\mathrm{kg} / \mathrm{m}^{2}\right)$ & $23.1 \pm 3.1$ & $21.7 \pm 2.0$ & $27.1 \pm 2.2$ & $<0.001$ \\
\hline Smoking status \{never/ex/light/heavy (\%)\} & 71.0/9.6/9.0/10.4 & 72.3/8.4/8.8/10.5 & $67.2 / 13.1 / 9.4 / 10.3$ & 0.073 \\
\hline Alcohol consumption \{never/light/moderate/heavy(\%)\} & $39.0 / 31.7 / 18.6 / 10.8$ & $40.7 / 30.3 / 19.0 / 10.0$ & 33.9/35.6/17.4/13.1 & 0.043 \\
\hline Systolic blood pressure $(\mathrm{mmHg})$ & $133 \pm 21$ & $132 \pm 21$ & $139 \pm 19$ & $<0.001$ \\
\hline Diastolic blood pressure $(\mathrm{mmHg})$ & $80 \pm 11$ & $79 \pm 11$ & $83 \pm 11$ & $<0.001$ \\
\hline Total cholesterol (mg/dL) & $201 \pm 35$ & $200 \pm 34$ & $204 \pm 35$ & 0.031 \\
\hline Triglycerides (mg/dL) & $90(68-127)$ & $85(64-117)$ & $108(81-153)$ & $<0.001$ \\
\hline HDL cholesterol (mg/dL) & $62 \pm 15$ & $64 \pm 16$ & $57 \pm 13$ & $<0.001$ \\
\hline LDL cholesterol (mg/dL) & $118 \pm 31$ & $116 \pm 31$ & $123 \pm 32$ & $<0.001$ \\
\hline Triglycerides/HDL cholesterol ratio & $1.5(1.0-2.3)$ & $1.3(0.9-2.0)$ & $1.9(1.3-3.2)$ & 0.001 \\
\hline Non-HDL cholesterol (mg/dL) & $139 \pm 34$ & $135 \pm 34$ & $148 \pm 34$ & $<0.001$ \\
\hline LDL-cholesterol/HDL-cholesterol ratio & $2.01 \pm 0.78$ & $1.92 \pm 0.74$ & $2.30 \pm 0.82$ & $<0.001$ \\
\hline Uric acid (mg/dL) & $5.0 \pm 1.4$ & $4.8 \pm 1.4$ & $5.5 \pm 1.4$ & $<0.001$ \\
\hline eGFR & $83.3 \pm 16.4$ & $83.4 \pm 16.1$ & $82.9 \pm 17.2$ & 0.659 \\
\hline Serum HMW adiponectin $(\mu \mathrm{g} / \mathrm{mL})$ & $3.0(4.9-8.0)$ & $5.4(3.2-8.7)$ & $3.9(2.2-5.8)$ & $<0.001$ \\
\hline Cardiovascular disease, \% & 4.7 & 4.8 & 4.3 & 0.771 \\
\hline
\end{tabular}

$\mathrm{HDL}$, high-density lipoprotein; LDL, low-density lipoprotein; eGFR, estimated glomerular filtration rate; HMW, high molecular weight. Data presented are mean \pm standard deviation. Data for triglycerides, TG/HDL-C ratio, and serum adiponectin were skewed, and are presented as median (interquartile range). Data for triglycerides, TG/HDL-C ratio, and serum adiponectin were log-transformed for analysis. ${ }^{*}$ Student's t-test or $\chi^{2}$ test.

significantly lower in that group. There were no intergroup differences in sex, smoking status, eGFR, and prevalence of CVD.

\section{Insulin resistance of subjects categorized by BMI}

Fasting blood glucose, IRI, and HOMA-IR were significantly higher in overweight subjects (Table 2), and prevalence of insulin resistance (HOMA-IR $>1.6$ or $>2.5$ ) was significantly higher in overweight subjects than in non-obese subjects.

Comparison of areas under ROC curves $(95 \% \mathrm{Cl})$ for potential markers of insulin resistance of subjects categorized by BMI

In non-obese subjects, the ROC curve analyses showed that the best marker of insulin resistance was LDL-C/
HDL-C ratio, with an area under the ROC curve of 0.74 (0.66-0.80) (Table 3; Figure 1). The TG/HDL-C ratio, HDL-C, and non-HDL-C also discriminated insulin resistance, as they had areas under the ROC curve of 0.31 (0.24-0.38), 0.69 (0.62-0.75) and 0.69 (0.62-0.75), respectively. In overweight subjects, TG and TG/HDL-C ratio were more effective.

\section{Optimal cut-off point of TG/HDL-C ratio and LDL-C/HDL-C ratio for predicting insulin resistance of subjects categorized by BMI}

Table 4 shows the cut-off points of TG/HDL-C ratio and LDL-C/HDL-C ratio for identifying insulin resistance. The optimal cut-off point to identifying insulin resistance for these markers yielded the following values: TG/HDL-C ratio of $\geq 1.50$ and LDL-C/HDL-C ratio of

Table 2 Insulin resistance of subjects categorized by body mass index

\begin{tabular}{|c|c|c|c|c|}
\hline & Total & Non-obese & Overweight & \\
\hline $\begin{array}{l}\text { Body mass index } \\
\text { Characteristics }\end{array}$ & $\begin{array}{c}\text { All } \\
\mathrm{N}=1,393\end{array}$ & $\begin{array}{c}<25.0 \mathrm{~kg} / \mathrm{m}^{2} \\
\mathrm{~N}=1,042\end{array}$ & $\begin{array}{c}\geq 25.0 \mathrm{~kg} / \mathrm{m}^{2} \\
\mathrm{~N}=351\end{array}$ & $P$-value* \\
\hline Fasting blood glucose (mg/dL) & $92(87-99)$ & $91(86-98)$ & $95(89-103)$ & $<0.001$ \\
\hline Immunoreactive insulin (mU/mL) & $5.1(3.4-7.6)$ & $4.5(3.0-6.5)$ & $8.0(5.3-11.2)$ & $<0.001$ \\
\hline HOMA-IR§ & $1.19(0.75-1.83)$ & $1.02(0.65-1.52)$ & $1.91(1.23-2.81)$ & $<0.001$ \\
\hline HOMA-IR§ $\leq 1.6, \%$ & 68.1 & 77.9 & 39.0 & \\
\hline HOMA-IRß $>1.6$ and $\leq 2.5, \%$ & 19.8 & 16.1 & 30.8 & $<0.001$ \\
\hline HOMA-IRß $>2.5, \%$ & 12.1 & 6.0 & 30.2 & $<0.001$ \\
\hline
\end{tabular}

HOMA-IR, homeostasis of minimal assessment of insulin resistance. Data for fasting blood glucose, fasting insulin, and HOMA-IR were skewed, and are presented as median (interquartile range). §HOMA-IR was calculated using the following formula; \{fasting blood glucose (FBG) (mg/dL) $X$ fasting Immunoreactive insulin $(\mathrm{mU} / \mathrm{mL})\} / 405$. Data for fasting blood glucose, fasting insulin, and HOMA-IR were log-transformed for analysis. *Student's $t$ test or $\chi^{2}$ test. 
Table 3 Comparison of areas under the ROC curves $(95 \% \mathrm{CI})$ for potential markers of insulin resistance (HOMA-IR§ > 2.5) of subjects categorized by body mass index

\begin{tabular}{|c|c|c|c|c|c|c|}
\hline \multirow[b]{3}{*}{$\begin{array}{l}\text { Body mass index } \\
\text { Characteristics }\end{array}$} & \multicolumn{5}{|c|}{ AUC $(95 \% \mathrm{Cl})$} & \multirow[b]{3}{*}{$P$-value } \\
\hline & \multirow{2}{*}{$\begin{array}{c}\text { Total } \\
\text { All } \\
\mathrm{N}=1,393\end{array}$} & \multicolumn{2}{|c|}{ Non-obese } & \multicolumn{2}{|c|}{ Overweight } & \\
\hline & & $P$-value & $\begin{array}{c}<25.0 \mathrm{~kg} / \mathrm{m}^{2} \\
\mathrm{~N}=1,042\end{array}$ & $P$-value & $\begin{array}{c}>25.0 \mathrm{~kg} / \mathrm{m}^{2} \\
\mathrm{~N}=351\end{array}$ & \\
\hline Triglycerides (mg/dL) & $0.69(0.45-0.73)$ & $<0.001$ & $0.66(0.59-0.72)$ & $<0.001$ & $0.64(0.58-0.71)$ & $<0.001$ \\
\hline HDL cholesterol (mg/dL) & $0.33(0.28-0.37)$ & $<0.001$ & $0.31(0.24-0.38)$ & $<0.001$ & $0.41(0.35-0.48)$ & 0.009 \\
\hline LDL cholesterol (mg/dL) & $0.61(0.56-0.65)$ & $<0.001$ & $0.65(0.58-0.72)$ & $<0.001$ & $0.54(0.48-0.61)$ & 0.188 \\
\hline Triglycerides/HDL cholesterol ratio & $0.70(0.66-0.75)$ & $<0.001$ & $0.69(0.62-0.75)$ & $<0.001$ & $0.64(0.57-0.70)$ & $<0.001$ \\
\hline Non-HDL cholesterol (mg/dL) & $0.66(0.61-0.70)$ & $<0.001$ & $0.69(0.62-0.75)$ & $<0.001$ & $0.59(0.52-0.65)$ & 0.011 \\
\hline LDL-cholesterol/HDL-cholesterol ratio & $0.69(0.65-0.73)$ & $<0.001$ & $0.74(0.66-0.80)$ & $<0.001$ & $0.58(0.51-0.65)$ & 0.021 \\
\hline
\end{tabular}

ROC, receiver operating characteristics; HOMA-IR, homeostasis of minimal assessment of insulin resistance; $\mathrm{Cl}$, confidence interval; $\mathrm{AUC}$, area under ROC curve; $\mathrm{HDL}$, high-density lipoprotein; LDL, low-density lipoprotein. §HOMA-IR was calculated using the following formula; \{fasting blood glucose (mg/dL) $\mathrm{X}$ immunoreactive insulin $(\mathrm{mU} / \mathrm{mL})\} / 405$.

$\geq 2.14$ in non-obese subjects, and $\geq 2.20, \geq 2.25$ in overweight. In non-obese subjects, the positive likelihood ratio value indicates that the odds of insulin resistance increased by 2.30 -fold if the LDL-C/HDL-C ratio was positive (the value 22.14 ). This ratio was greater for LDL-C/HDL-C ratio than TG/HDL-C ratio. The negative likelihood ratios indicate the extent to which the odds of insulin resistance decrease if the test is negative. These odds also decreased more so for LDL-C/HDL-C ratio. In overweight subjects, these values were similar.

\section{Discussion}

In the present study, we examined whether lipid profiles (i.e., TG, HDL-C, LDL-C, TG/HDL-C ratio, LDL-C/
HDL-C ratio and non-HDL-C) were associated with insulin resistance in Japanese adults, categorized by body mass index. Most fundamental is the fact that not all overweight or obese persons are insulin resistant. In non-obese subjects, $6.0 \%$ of them were insulin resistant, and the best marker of insulin resistance was LDL-C/ HDL-C ratio, but HDL-C, TG/HDL-C ratio and nonHDL-C also discriminated insulin resistance. In overweight subjects, the areas of TG and TG/HDL-C ratio were greater than those of the other parameters. The optimal cut-off point to identifying insulin resistance for these markers yielded the following values: TG/HDL-C ratio of $\geq 1.50$ and LDL-C/HDL-C ratio of $\geq 2.14$ in nonobese subjects, and $\geq 2.20$ and $\geq 2.25$, respectively in

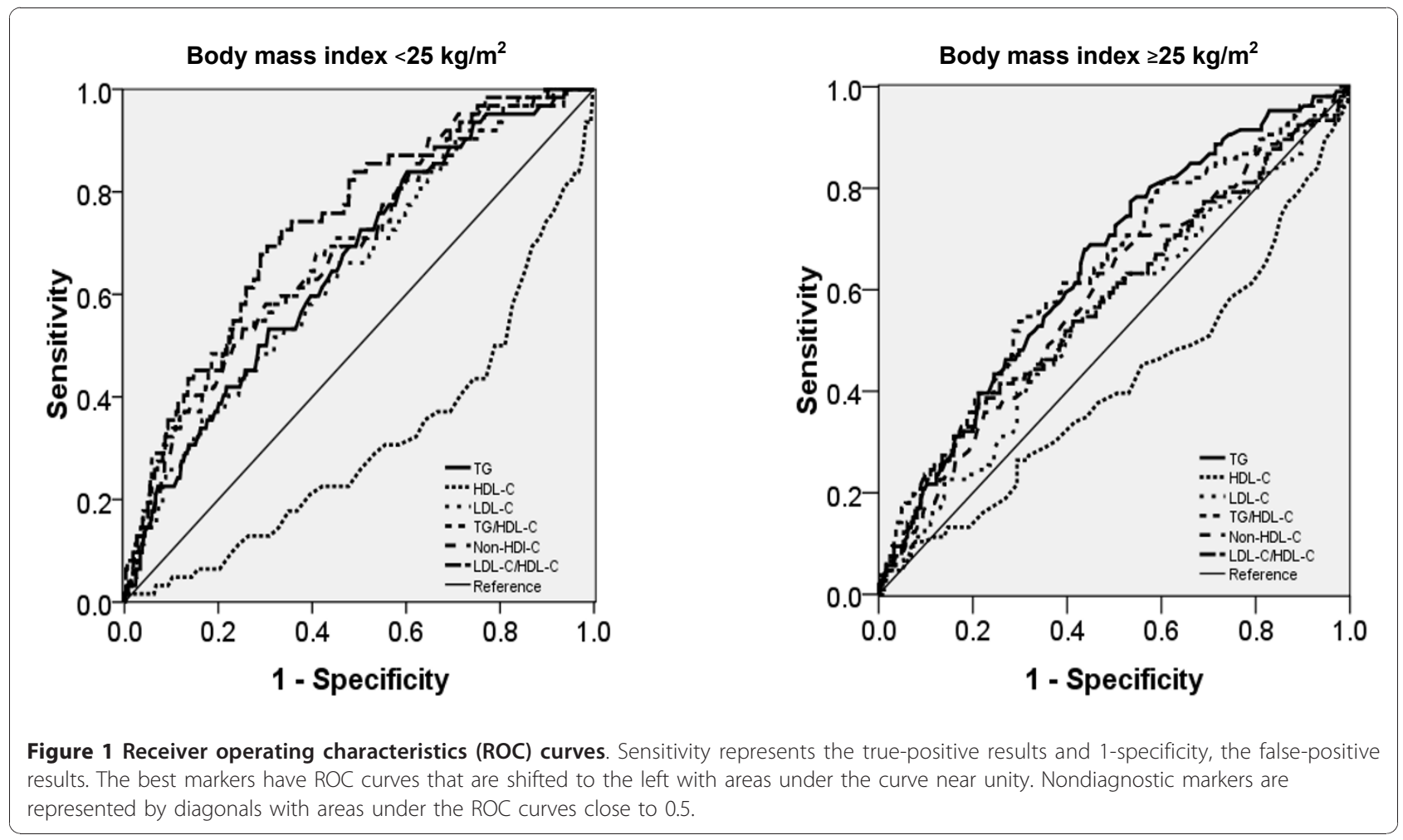


Table 4 Comparison of triglyceride/HDL cholesterol ratio and LDL cholesterol/ HDL cholesterol ratio for predicting of insulin resistance (HOMA-IR§ > 2.5) of subjects categorized by body mass index

\begin{tabular}{|c|c|c|c|c|c|c|c|}
\hline \multirow[b]{2}{*}{ Cut-off point Characteristics } & \multicolumn{2}{|c|}{ HOMA-IR§ } & \multirow[b]{2}{*}{ Sensitivity } & \multirow[b]{2}{*}{ Specificity } & \multirow[b]{2}{*}{ Positive LR } & \multirow[b]{2}{*}{ Negative LR } & \multirow[b]{2}{*}{ Accuracy } \\
\hline & $\leq 2.5$ & $>2.5$ & & & & & \\
\hline Body mass indext $<25.0 \mathrm{~kg} / \mathrm{m}^{2}$ & $N=980$ & $N=62$ & & & & & $\%$ \\
\hline Triglycerides/HDL cholesterol ratio $<1.50$ & 580 & 20 & 0.67 & 0.59 & 1.63 & 0.56 & 59.7 \\
\hline Triglycerides/HDL cholesterol ratio $\geq 1.50$ & 400 & 42 & & & & & \\
\hline LDL cholesterol/HDL cholesterol ratio $<2.14$ & 682 & 19 & 0.69 & 0.70 & 2.30 & 0.44 & 69.6 \\
\hline LDL cholesterol/HDL cholesterol ratio $\geq 2.14$ & 298 & 43 & & & & & \\
\hline Body mass index $t \geq 25.0 \mathrm{~kg} / \mathrm{m}^{2}$ & $N=245$ & $N=106$ & & & & & \\
\hline Triglycerides/HDL cholesterol ratio $<2.20$ & 157 & 45 & 0.57 & 0.64 & 1.58 & 0.67 & 62.1 \\
\hline Triglycerides/HDL cholesterol ratio $\geq 2.20$ & 88 & 61 & & & & & \\
\hline LDL cholesterol/HDL cholesterol ratio $<2.25$ & 143 & 49 & 0.59 & 0.58 & 1.40 & 0.71 & 57.0 \\
\hline LDL cholesterol/HDL cholesterol ratio $\geq 2.25$ & 102 & 57 & & & & & \\
\hline
\end{tabular}

HOMA-IR, homeostasis of minimal assessment of insulin resistance; LR, likelihood ratio; HDL, high-density lipoprotein; LDL, low-density lipoprotein. §HOMA-IR was calculated using the following formula; (fasting blood glucose $(\mathrm{mg} / \mathrm{dL}) \mathrm{X}$ immunoreactive insulin $(\mathrm{mU} / \mathrm{mL})) / 405$.

overweight. The positive likelihood ratio was greatest for LDL-C/HDL-C ratio in non-obese subjects. Lipid ratio of LDL-C/HDL-C might be used as an integrated and simple lipid measure to evaluate insulin resistance in non-obese subjects.

Resistance to insulin-mediated glucose disposal is distributed continuously through the general population [15], and we have no criterion with which to identify a participant as being insulin resistance or insulin sensitive. However, we classified a participant as insulin resistant if he or she was in HOMA-IR > 2.5 [14]. Previous studies have shown that HOMAIR-based insulin resistance scores strongly correlate with glucose clamp-assessed insulin resistance $[13,15]$. However, the validation was carried out in only a few subjects, and HOMA-IR is less accurate and precise than the glucose clamp in measuring insulin resistance, but this limitation is mitigated when the number of subjects examined is large, as in our study [16].

Hypertriglyceridemia and low HDL-C almost never occurred as isolated disorders, and were nearly always associated with insulin resistance because insulin affects very low-density lipoprotein and HDL-C metabolism [17]. In previous studies, several lipid ratios have been proposed as simple and useful clinical indicators of insulin resistance. The TG/HDL-C, the T-C/HDL-C, and the LDL-C/HDL-C ratio have shown similar potential for insulin resistance, though the reports are not entirely consistent. In 50 white Americans, both TG and TG/ HDL-C ratio were acceptable markers for insulin resistance, with area under the ROC curve of 0.763 and 0.770 , respectively, but poor predictors in 99 African Americans, with the values at 0.625 and 0.639 , respectively [18]. It was demonstrated that the relationship between TG and TG/HDL-C with insulin resistance differs by ethnicity. In 3,014 patients (mean age 54 years; $55 \%$ women), TG/HDL-C ratio and $\mathrm{T}-\mathrm{C} / \mathrm{HDL}-\mathrm{C}$ ratio were related to insulin resistance assessed by the top quartile of the HOMA-IR, and the area under the ROC curves for predicting insulin resistance with TG/HDL-C ratio and $\mathrm{T}-\mathrm{C} / \mathrm{HDL}-\mathrm{C}$ ratio were 0.745 and 0.707 , respectively [19]. LDL-C/HDL-C ratio [20] as well as TG/HDL-C ratio [21] have advantages for standardization and identification of patients with an atherogenic lipoprotein profile as a surrogate maker of insulin resistance. Also in our study, both LDL-C/HDL-C and TG/ HDL-C ratio were useful makers of insulin resistance, especially in all subjects or non-obese subjects. However, these makers were weaker in overweight subjects. Kimm et al. [21] demonstrated that the lipid ratios of $\mathrm{TC} /$ HDL-C, LDL-C/HDL-C and TG/HDL-C, as well as TG and HDL-C, were consistently associated with metabolic syndrome and insulin resistance in participants without metabolic syndrome, though these relations were weaker in participants with metabolic syndrome. Lipid ratios that include information on at least two measures might have a more integrated explanation than single lipid measures such as TG or HDL-C [21].

Some limitations of this study must be considered. First, the response rate was as low as $35 \%$ that is usually the casein other conventional community studies in Japan. However, the relatively large sample size enabled the assessment of an extensive array of insulin resistances in relation to lipid profiles. Second, the crosssectional study design is limited in its ability to eliminate causal relationships between lipid profiles and HOMA-IR. Third, our definition of HOMA-IR is based on a single assessment of FBS and IRI, which may introduce misclassification bias. Therefore the demographics and referral source may limit generalizability.

In conclusion, the present study demonstrated that special lipid profiles are associated with insulin resistance according to BMI in a general population. The ability to identify who is non-obese or overweight and who are insulin resistant could help health care 
professionals in bringing about lifestyle interventions. In that context, use of the cutoff-points of LDL-C/HDL-C ratio or TG/HDL-C ratio described in this report is simple and useful. The present data documented that insulin resistance was present even in subjects with BMI within the normal range. Further prospective population-based studies are needed to investigate the changes in lipid metabolism by lifestyle interventions.

\section{Acknowledgements}

This work was supported in part by a grant-in-aid for Scientific Research from the Foundation for Development of Community (2009).

\section{Author details}

'Department of Community Medicine, Ehime University Graduate School of Medicine; Ehime 791-0295, Japan. ${ }^{2}$ Geriatric Medicine, Ehime University Graduate School of Medicine; Ehime 791-0295, Japan. ${ }^{3}$ Department of Internal Medicine, Seiyo Municipal Nomura Hospital, Ehime 797-1212, Japan.

\section{Authors' contributions}

RK, YT, and KK participated in the design of the study, performed the statistical analysis and drafted the manuscript. NO, TaK, and ToK contributed to acquisition of data and its interpretation. ST and MA contributed to conception and design of the statistical analysis. TM conceived of the study, participated in its design, coordination and helped to draft the manuscript. All authors read and approved the manuscript.

\section{Competing interests}

The authors declare that they have no competing interests.

Received: 7 October 2010 Accepted: 7 December 2010

Published: 7 December 2010

\section{References}

1. Organization of the Ministry of Health, Labour and Welfare: 2006, 173-175 [http://www.mhlw.go.jp/bunya/kenkou/eiyou09/d//01-03.pdf].

2. Lee IM, Manson JE, Hennekens CH, Paffenbarger RS Jr: Body weight and mortality. A 27-year follow-up of middle-aged men. JAMA 1993, 270(23):2823-2828

3. Manson JE, Willett WC, Stampfer MJ, Colditz GA, Hunter DJ, Hankinson SE: Body weight and mortality among women. N Engl J Med 1995, 333(11):677-685.

4. Calle EE, Thun MJ, Petrelli JM, Rodriguez C, Heath CW: Body-mass index and mortality in a prospective cohort of U.S. adults. N Engl I Med 1999, 341(15):1097-1105.

5. Ruderman NB, Schneider SH, Berchtold P: The "metabolically-obese," normal-weight individual. Am J Clin Nutr 1981, 34(8):1617-1621.

6. Kawamoto R, Ohtsuka N, Ninomiya D, Nakamura S: Carotid atherosclerosis in normal-weight metabolic syndrome. Intern Med 2007, 46(21):1771-1777.

7. Trirogoff ML, Shintani A, Himmelfarb J, Ikizler TA: Body mass index and fat mass are the primary correlates of insulin resistance in nondiabetic stage 3-4 chronic kidney disease patients. Am J Clin Nutr 2007, 86(6):1642-1648.

8. Reaven GM: Insulin resistance, the insulin resistance syndrome, and cardiovascular disease. Panminerva Med 2005, 47(4):201-210.

9. Laws $A$, Reaven $G M$ : Evidence for an independent relationship between insulin resistance and fasting plasma HDL-cholesterol, triglyceride and insulin concentrations. J Intern Med 1992, 231(1):25-30.

10. McLaughlin T, Abbasi F, Cheal K, Chu J, Lamendola C, Reaven G: Use of metabolic markers to identify overweight individuals who are insulin resistant. Ann Intern Med 2003, 139(10):802-809.

11. Jeppesen J, Facchini FS, Reaven GM: Individuals with high total cholesterol/ HDL cholesterol ratios are insulin resistant. J Intern Med 1998, 243(4):293-298.

12. Friedewald WT, Levy RI, Fredrickson DS: Estimation of the concentration of low-density lipoprotein cholesterol in plasma, without use of the preparative ultracentrifuge. Clin Chem 1972, 18(6):499-502.
13. Matthews DR, Hosker JP, Rudenski AS, Naylor BA, Treacher DF, Turner RC: Homeostasis model assessment: insulin resistance and beta-cell function from fasting plasma glucose and insulin concentrations in man. Diabetologia 1985, 28(7):412-419.

14. Taniguchi A, Fukushima M, Sakai M, Kataoka K, Miwa K, Nagata I, Doi K, Tokuyama K, Nakai Y: Insulin-sensitive and insulin-resistant variants in nonobese Japanese type 2 diabetic patients. The role of triglycerides in insulin resistance. Diabetes Care 1999, 22(12):2100-2101.

15. Yeni-Komshian H, Carantoni M, Abbasi F, Reaven GM: Relationship between several surrogate estimates of insulin resistance and quantification of insulin-mediated glucose disposal in $\mathbf{4 9 0}$ healthy nondiabetic volunteers. Diabetes Care 2000, 23(2):171-175.

16. Bonora E, Kiechl S, Willeit J, Oberhollenzer F, Egger G, Targher G, Alberiche M, Bonadonna RC, Muggeo M: Prevalence of insulin resistance in metabolic disorders: the Bruneck Study. Diabetes 1998, 47(10):1643-1649.

17. Lewis GF, Uffelman KD, Szeto LW, Steiner G: Effects of acute hyperinsulinemia on VLDL triglyceride and VLDL apoB production in normal weight and obese individuals. Diabetes 1993, 42(6):833-842.

18. Kim-Dorner SJ, Deuster PA, Zeno SA, Remaley AT, Poth M: Should triglycerides and the triglycerides to high-density lipoprotein cholesterol ratio be used as surrogates for insulin resistance? Metabolism 2010, 59(2):299-304.

19. Kannel WB, Vasan RS, Keyes MJ, Sullivan LM, Robins SJ: Usefulness of the triglyceride-high-density lipoprotein versus the cholesterol-high-density lipoprotein ratio for predicting insulin resistance and cardiometabolic risk (from the Framingham Offspring Cohort). Am J Cardiol 2008, 101(4):497-501.

20. Tamada M, Makita S, Abiko A, Naganuma Y, Nagai M, Nakamura M: Lowdensity lipoprotein cholesterol to high-density lipoprotein cholesterol ratio as a useful marker for early-stage carotid atherosclerosis. Metabolism 2010, 59(5):653-657.

21. Kimm H, Lee SW, Lee HS, Shim KW, Cho CY, Yun JE, Jee SH: Associations between lipid measures and metabolic syndrome, insulin resistance and adiponectin. - Usefulness of lipid ratios in Korean men and women Circ J 2010, 74(5):931-937.

doi:10.1186/1476-511X-9-138

Cite this article as: Kawamoto et al:: Low-density lipoprotein cholesterol to high-density lipoprotein cholesterol ratio is the best surrogate marker for insulin resistance in non-obese Japanese adults. Lipids in Health and Disease 2010 9:138.

\section{Submit your next manuscript to BioMed Central and take full advantage of:}

- Convenient online submission

- Thorough peer review

- No space constraints or color figure charges

- Immediate publication on acceptance

- Inclusion in PubMed, CAS, Scopus and Google Scholar

- Research which is freely available for redistribution
C Biomed Central 